\title{
Lipid Lowering Drugs: Present Status and Future Developments
}

\author{
Massimiliano Ruscica ${ }^{1}$ - Nicola Ferri ${ }^{2}$ - Raul D. Santos ${ }^{3,4}$ - Cesare R. Sirtori ${ }^{1}$ - Alberto Corsini ${ }^{1,5}$
}

Accepted: 11 February 2021 / Published online: 10 March 2021

(C) The Author(s) 2021

\begin{abstract}
Purpose of review Based on the recent data of the DA VINCI study, it is clear that, besides utilization of statins, there is a need to increase non-statin lipid lowering approaches to reduce the cardiovascular burden in patients at highest risk.

Recent findings For hypercholesterolemia, the small synthetic molecule bempedoic acid has the added benefit of selective liver activation, whereas inclisiran, a hepatic inhibitor of the PCSK9 synthesis, has comparable effects with PCSK9 monoclonal antibodies. For hypertriglyceridemia, cardiovascular benefit has been achieved by the use of icosapent ethyl, whereas results with pemafibrate, a selective agonist of PPAR- $\alpha$, are eagerly awaited. In the era of RNA-based therapies, new options are offered to dramatically reduce levels of lipoprotein(a) $\left(\mathrm{APO}(\mathrm{a}) \mathrm{L}_{\mathrm{RX}}\right.$ ) and of triglycerides (ANGPTL3 $\mathrm{L}_{\mathrm{RX}}$ and APOCIII- $\mathrm{L}_{\mathrm{Rx}}$ ).

Summary Despite the demonstrated benefits of statins, a large number of patients still remain at significant risk because of inadequate LDL-C reduction or elevated blood triglyceride-rich lipoproteins or lipoprotein(a). The area of lipid modulating agents is still ripe with ideas and major novelties are to be awaited in the next few years.
\end{abstract}

Keywords APOCIII- $\mathrm{L}_{\mathrm{Rx}} \cdot \mathrm{ANGPTL} \mathrm{L}_{\mathrm{RX}} \cdot \operatorname{Inclisiran} \cdot \operatorname{Lipoprotein}(\mathrm{a}) \cdot$ Proprotein convertase subtilisin/kexin type 9

\section{Introduction}

Atherosclerotic cardiovascular disease (ASCVD) encompassing pathologies caused by atherosclerosis within the coronary, cerebral, and peripheral arteries and the aorta is a leading cause of death and disability worldwide [1]. Among the risk factors accounting for this condition (nine have been identified in the INTERHEART study), lipid/ lipoprotein abnormalities play a central role in this process [2]. Although epidemiologic, genetic, and clinical intervention studies have unquestionably identified low-density lipoprotein cholesterol (LDL-C) to be causal in this process [3, 4], the contribution of triglycerides (TG) to cardiovascular risk is

This article is part of the Topical Collection on Statin Drugs

Massimiliano Ruscica

massimiliano.ruscica@unimi.it

Alberto Corsini

alberto.corsini@unimi.it

Nicola Ferri

nicola.ferri@unipd.it

Raul D. Santos

rauldsf@gmail.com

Cesare R. Sirtori

cesare.sirtori@icloud.com also evident from long-term prospective and genetic studies $[5,6]$.

While the scientific evidence for reducing LDL-C is definitely strong, i.e., the more LDL-C is reduced the larger will be the ASCVD risk reduction [7, 8], a substantial residual risk persists. This is especially evident among high risk subjects with familial combined hyperlipidemia, familial hypertriglyceridemia as well as in those with the metabolic syndrome, type 2 diabetes mellitus (T2DM) and the related atherogenic dyslipidemia (reviewed in [9, 10]). This last is characterized by elevated serum TG, increased remnant lipoproteins, and low levels of highdensity lipoprotein cholesterol (HDL-C) [11]. Very

1 Department of Pharmacological and Biomolecular Sciences, Università degli Studi di Milano, Milan, Italy

2 Department of Pharmaceutical and Pharmacological Sciences, Università degli Studi di Padova, Padova, Italy

3 Lipid Clinic, Heart Institute (InCor), University of Sao Paulo, São Paulo, Brazil

4 Hospital Israelita Albert Einstein, São Paulo, Brazil

5 IRCCS MultiMedica, Sesto S. Giovanni, Milan, Italy 
recently, hypertriglyceridemia in statin-treated T2DM patients was directly associated with a raised ASCVD risk after coronary revascularization [12]. Although not in the remit of this review article, it is worth mentioning that the elevated risk conferred by reduced HDL-C levels has not been as yet fully addressed by targeted therapies, whereas administration of recombinant HDL in different forms is still undergoing clinical evaluation $[13,14]$.

Finally, more extensive epidemiological evaluation of the lipoprotein profile of high-risk patients also brought attention to elevated levels of lipoprotein(a) [Lp(a)], a lipoprotein composed of an LDL-like particle, covalently bound to apo(a) and associated with a raised ASCVD risk [15]. On an equimolar basis, $\mathrm{Lp}(\mathrm{a})$ is more atherogenic than LDL because it carries all the proatherogenic components of LDL as well as apo(a), that binds phosphocholine containing oxidized phospholipids [16]. Apo(a) seems to mediate atherothrombosis by enhancing inflammation and by potential antifibrinolytic effects (e.g., inhibition of plasminogen activation and of fibrin degradation) [17].

Thus, the present review will focus on the current status of novel pharmacological approaches to these more recently investigated lipoprotein abnormalities. Some of the described newer drugs affect more than one lipoprotein abnormality, whereas others have a complex mechanism resulting in multimodal changes of the lipoprotein profile.

\section{Novelties in High LDL-Cholesterol Treatment}

LDL-C lowering is the mainstay of drug treatment for highrisk patients. Statins, from older less powerful molecules such as pravastatin, have developed into more effective agents acting at lower doses (pitavastatin) and with potential LDL-C reductions of over 50\% (rosuvastatin and atorvastatin) [18]. Besides the $\mathrm{CV}$ benefit shown in patients with coronary artery disease, the use of intensive lipid-lowering therapy with statins is also recommended after ischemic stroke of atherosclerotic origin. As recently reported in a parallel-group trial conducted in France and South Korea, among patients with evidence of cerebrovascular or coronary-artery atherosclerosis, those achieving a target LDL-C $\leq 70 \mathrm{mg} /$ $\mathrm{dL}$ had a lower risk of major cardiovascular events compared to patients reaching an LDL-C range between 90 and $110 \mathrm{mg} / \mathrm{dL}$ [19].

In the attempt to reduce the ASCVD burden driven by LDL-C, as also corroborated by Mendelian randomization analyses [3], the use of inhibitors of the proprotein convertase subtilisin/kexin type 9 (PCSK9) has provided a very powerful additional therapy for hypercholesterolemia, allowing to set LDL-C targets $\leq 55 \mathrm{mg} / \mathrm{dL}$, as in cases of secondary prevention in very high-risk patients or in familial hypercholesterolemia [8].

\section{PCSK9 Inhibition by Monoclonal Antibodies}

The efficacy and safety of the two available monoclonal antibodies evolocumab and alirocumab have been extensively evaluated in the FOURIER and ODYSSEY OUTCOMES studies, respectively, as well as in the subsequent sub-analyses. Briefly, as reviewed by our group [20], in the FOURIER study enrolling patients with ASCVD, evolocumab was superior to placebo in reducing the major adverse cardiac events (MACEs) by $15 \%$, an effect primarily driven by a decrement in MI $(-27 \%)$, stroke $(-21 \%)$ and coronary revascularization $(-22 \%)$ [21]. Overall, although the benefit of evolocumab was similar across a broad range of ages and regardless of sex [22], patients who experienced a greater absolute risk reduction were those at higher risk for major vascular events e.g., those with greater atherosclerotic plaque burden[23], with peripheral artery disease [24] or with recent MI $\left[25^{\bullet}, 26\right]$. Finally, the benefit of adding PCSK9 to statins was evident also in patients with diabetes [27], metabolic syndrome [28], as well as in those with prior ischemic stroke [29].

In the case of alirocumab, the ODYSSEY OUTCOMES trial has shown the superiority of alirocumab vs placebo in reducing MACEs by 15\% (a composite of cardiovascular death, non-fatal MI, fatal or non-fatal ischemic stroke, or unstable angina requiring hospitalization) in patients with an acute coronary syndrome. This benefit was evident irrespective of age [30] and independent of baseline eGFR, across a broad range above $30 \mathrm{~mL} / \mathrm{min} / 1.73 \mathrm{~m}^{2}$, with larger relative risk reductions in patients with eGFR $>60 \mathrm{~mL} / \mathrm{min} / 1.73 \mathrm{~m}^{2}$ [31]. Other major findings associated with alirocumab were the risk reduction of stroke (a benefit independent of the history of cerebrovascular disease [32]) and of total hospitalizations with a corresponding small rise in days alive and out of hospital [33].

In addition, when comparing the two trials, a stratification based on polygenic risk scores for coronary artery disease showed that individuals who derived a larger absolute and relative risk reduction were those with a high score $[34,35]$. In a similar way, as reported in a recent meta-analysis of the two outcome trials, both monoclonal antibodies led to a $31 \%$ reduction in the risk of venous thromboembolism [36].

Finally, as elsewhere reviewed by our group [37], although there is no impact of PCSK9 monoclonal antibodies on highsensitivity C-reactive protein (hsCRP), this biomarker identifies patients with a high CV risk, achieving better ASCVD prevention after treatment [38].

\section{PCSK9 Inhibition by Silencing RNA}

A newer approach to inhibit PCSK9 has been provided by inclisiran, a siRNA currently under investigation. Inclisiran, specifically designed to target the $3^{\prime}$ UTR of the PCSK9 mRNA, is a long-acting siRNA whose $3^{\prime}$ end of the passenger 
strand is functionalized with triantennary GalNAc (review in [39]) (Fig. 1). Aside from the ORION 1 study whose positive results have been extensively reviewed elsewhere [41], the safety and efficacy of inclisiran have been evaluated by the still ongoing ORION program. ORION-10 (conducted in US) and -11 (conducted in Europe and South Africa) recruited patients with ASCVD or ASCVD risk-equivalent. The ORION-2, -5 and -9 trials have recruited instead familial hypercholesterolemia (FH) patients, whereas ORION-3 and -8 were single-arm, open label studies. Dose interval was $300 \mathrm{mg}$ injected on day 1 and another dose on day 90, thereafter treatment being administered every 180 days (at day 270 and 450). Relative to this choice, it is worth mentioning that although inclisiran has a short plasma half-life (5-10 h), its long-lasting effect on LDL-C is possibly due to the entrapment of inclisiran in the endosomes which may serve as an intracellular depot of drug, slowly releasing it over time [42].

ORION-9 enrolled 482 heterozygous FH adult patients with mean baseline LDL-C of $153 \mathrm{mg} / \mathrm{dL}$ despite maximum tolerated lipid lowering drugs and followed for 18 months (510 days). A $1.5 \mathrm{~mL}$ sc injection of a $300 \mathrm{mg}$ dose of inclisiran (corresponding to $284 \mathrm{mg}$ of inclisiran free acid) led to an absolute change in LDL-C of $-47.9 \%$ (95\% CI, -53.5 to $-42.3, \mathrm{p}=0.001$ ) with a time-averaged percent change of $-44.3 \%$ (between group difference). At day 510 , the levels of circulating PCSK9 were decreased by $60.7 \%$ in the inclisiran group and raised by $17.7 \%$ in the placebo group. Treatment was associated with a higher percentage of local injection-related side effects vs placebo (17.0\% vs $1.7 \%)$, the majority of events being rated as mild and none as serious. Low-titer antidrug antibodies were detected in $2.6 \%$ of the sample (25 samples from 18 patients), apparently not associated with changes in clinical endpoints [43].

In the US-based ORION-10 study, a 510-day treatment with inclisiran was superior to placebo in reducing LDL-C (-52.3\%; 95\%CI, 48.8 to 55.7). Among the serious adverse events, $\mathrm{CV}$ deaths were $7(0.9 \%)$ in the inclisiran arm vs 5 $(0.6 \%)$ in the placebo group, fatal/non-fatal MI were 21 $(2.6 \%)$ with inclisiran and $18(2.3 \%)$ with placebo. The prespecified exploratory $\mathrm{CV}$ end points were $58(7.4 \%)$ in patients given inclisiran and $79(10.2 \%)$ in those on placebo. Despite the same dramatic reduction in LDL-C $(-49.9 \%$; $95 \%$ CI, 46.6 to 53.1 ), in the non-US based ORION-11 trial, CV deaths were $9(1.1 \%)$ with inclisiran and $10(1.2 \%)$ with placebo, 10 fatal/non-fatal MI (1.2\%) with inclisiran and 22 $(2.7 \%)$ with placebo. The prespecified exploratory CV end points were $63(7.8 \%)$ and $83(10.3 \%)$, respectively. A meta-analysis on MACE in ORION-10 and -11 trials found that the benefit of LDL lowering achieved with inclisiran is in concordance with the results of 7 trials involving treatment

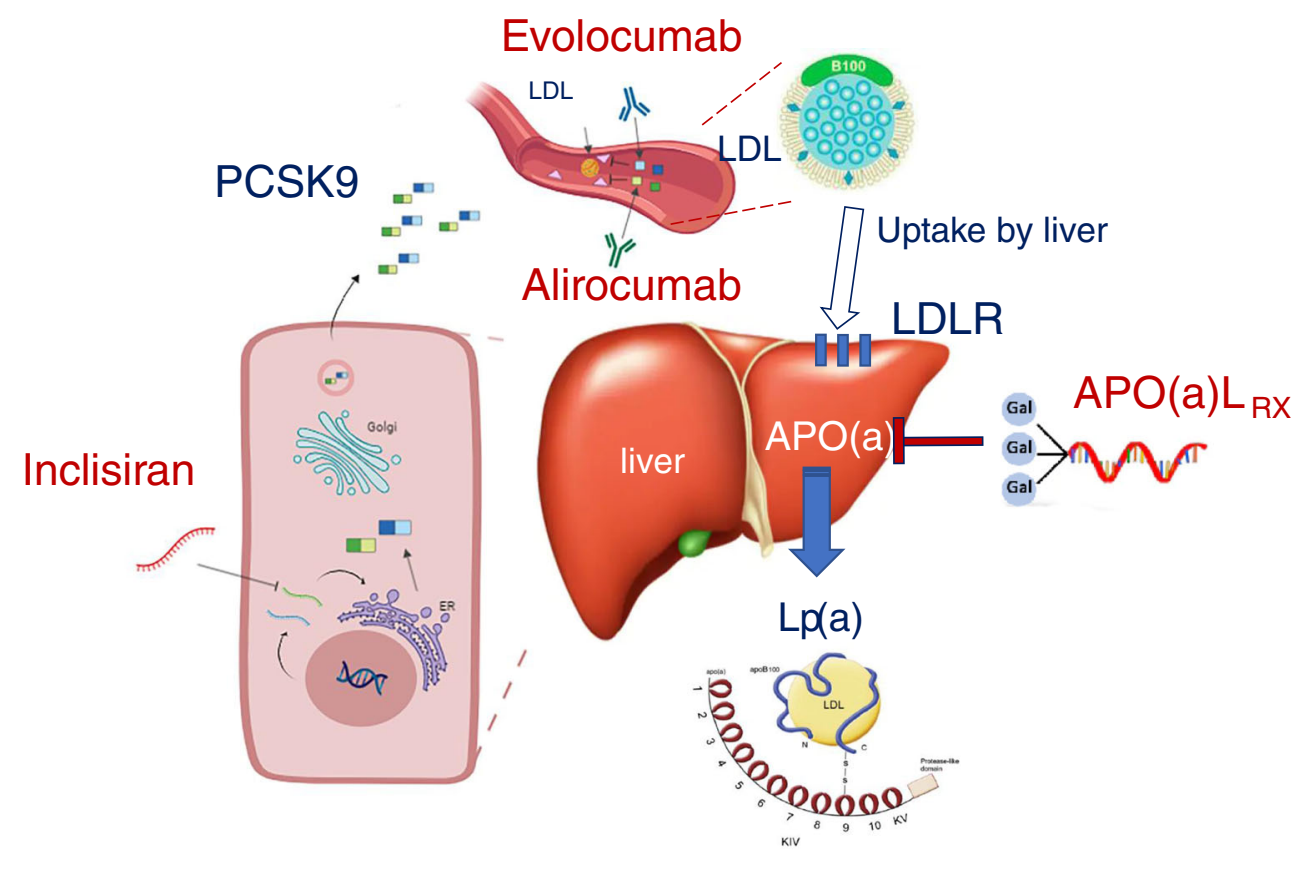

Fig. 1 Molecular mechanisms of PCSK9 and Lp(a) inhibition. PCSK9, mainly derived from the liver, acts by degrading the LDLR expressed on hepatocytes. PCSK9 inhibition leads to higher LDLR expression, thus lowering plasma LDL cholesterol. Inclisiran by inhibiting the transcription of the PCSK9 mRNA reduces the total amount of circulating PCSK9. Conversely, monoclonal antibodies (evolocumab and alirocumab) block PCSK9 interaction with LDLR. Both therapies have shown to strongly reduce the LDL-C levels. Relative to Lp(a) lowering, IONIS-APO(a)Lrx is a ligand-conjugated ASO with a triantennary $\mathrm{N}$-acetylgalactosamine (GalNAc) covalently attached, to allow rapid and specific uptake by hepatocytes. ASO, antisense oligonucleotide; LDLR, low-density lipoprotein receptor; Lp(a), lipoprotein(a); PCSK9, proprotein convertase subtilisin/kexin type 9. Adapted with permission of Elsevier [40]. 
with monoclonal PCSK9 inhibitors (the OSLER I-II trials, the ODYSSEY Long Term, the GLAGOV trial, the FOURIER trial, the SPIRE I-II and the ODYSSEY Outcomes trials) [44]. The still recruiting ORION-4 trial on coronary patients will clarify the CV benefit of this agent [45••] (Table 1 ).

Finally, ORION-7 (conducted in New Zealand) was a phase 1, open-label study evaluating the effect of renal impairment on pharmacokinetics (PK), pharmacodynamics (PD), safety, and tolerability of a single s.c. dose of inclisiran sodium $300 \mathrm{mg}$. Since renal clearance is the main route of elimination of inclisiran, with approximately one-third of the total administered does detected in urine within $24 \mathrm{~h}$, patients were allocated to four groups based on renal function: normal (creatinine clearance $-\mathrm{CrCl} \geq 90 \mathrm{~mL} / \mathrm{min})$, mild $(\mathrm{CrCl} 60-89 \mathrm{~mL} /$ $\mathrm{min})$, moderate $(\mathrm{CrCl} 30-50 \mathrm{~mL} / \mathrm{min})$, and severe $(\mathrm{CrCl} 15-$ $29 \mathrm{~mL} / \mathrm{min}$ ) renal impairment. The renal clearance of inclisiran was reduced proportionally to the degree of renal impairment. Relative to PD effects or safety profile, there were no differences among individuals with normal renal function and patients with mild, moderate or severe renal impairment. Moreover, at day 60, the plasma levels of PCSK9 were reduced by $68.1 \% \pm 12.4 \%$ in the group with normal renal function, by $74.2 \% \pm 12.3 \%, 79.8 \% \pm 4.9 \%$, and by $67.9 \% \pm 16.4 \%$, respectively, in those with mild, moderate, and severe renal impairment [48].

\section{Bempedoic Acid}

This compound is a linear chain molecule acting as a selective antagonist of ATP citrate lyase (ACLY), an important step in both fatty acid and cholesterol biosynthesis. Inhibition of ACLY leads, in fact, to a reduction of acetyl-CoA, the direct precursor of $\mathrm{HMG}-\mathrm{CoA}$, thus leading to an increased activity of LDL-receptors with reduction of plasma cholesterol [49]. In addition, bempedoic acid activates AMPK in different cell types potentially leading to an improvement in insulin resistance [50], with the potential of not increasing the diabetes risk. Pooled data from four phase 3 clinical trials reported that a new-onset diabetes/hyperglycemia occurred less frequently with bempedoic acid vs placebo [51].

Bempedoic acid is a prodrug, activated by acyl-CoA synthetase-1 only in the liver, thus excluding the potential of exerting any action on skeletal muscle [49]. Indeed, looking at the clinical trials, there is essentially no occurrence of significant muscular side effects [52]. As recently reported, the analyses of phase 3 trials (CLEAR Tranquility, CLEAR Harmony, CLEAR Wisdom, and CLEAR Serenity) showed that bempedoic acid reduced LDL-C roughly by $18 \%$ when given on-top of statins and by $24 \%$ when given as a monotherapy [53]. The drug is also available in a fixed dose combination $(180 \mathrm{mg})$ with ezetimibe $(10 \mathrm{mg})$ leading to potential LDL-C reduction of $41 \%$ [54]. Similar to statins, treatment with bempedoic acid markedly reduces hsCRP levels [38]. Relative to safety, a modest increase in blood urea nitrogen, creatinine, and uric acid and a decrement in hemoglobin were found in treated patients. A raised incidence of gout was found with bempedoic acid (1.6/100 person-years) vs $0.5 / 100$ person-years for those allocated to placebo [51]. A very recent meta-analysis of $\mathrm{CV}$ outcomes from 4 studies on a total of 3,483 patients indicated $17 \%$, non-statistically significant reduction of five-point MACE with, however, a surprising $50 \%$ lowering of non-coronary revascularizations [55]. On this matter, although a Mendelian randomization analysis predicted a reduction in CVD risk per unit decrease in the LDL-C levels in carriers of loss-of-function mutation in ACLY similar to that obtained in carriers of loss-of-function for $H M G C R$ [56], as yet no clinical reports of adequate duration on $\mathrm{CV}$ event reduction have been published. A large secondary prevention study in 12,000 statin intolerant patients is ongoing and should be reported in the first quarter of 2022 [46] (Table 1).

\section{Angiopoietin-like Protein 3}

A somewhat unexpected development in the field of cholesterol lowering medications has been that of antagonists of

Table 1 Ongoing outcome trials

\begin{tabular}{|c|c|c|}
\hline & Outcome studies & Description \\
\hline Inclisiran & ORION-4 & $\begin{array}{l}\text { A double-blind randomized placebo-controlled trial assessing the effects of inclisiran on } \\
\text { clinical outcomes among people with atherosclerotic cardiovascular disease (NCT03705234) }\end{array}$ \\
\hline Bempedoic acid & CLEAR Outcomes [46] & $\begin{array}{l}\text { To determine if treatment with bempedoic acid (ETC-1002) versus placebo decreases the } \\
\text { risk of cardiovascular events in patients who are statin intolerant (NCT02993406) }\end{array}$ \\
\hline TQJ230 or APO(a)Lrx & Lp(a)HORIZON & $\begin{array}{l}\text { Assessing the impact of lipoprotein (a) lowering with TQJ230 on major cardiovascular } \\
\text { events in patients with CVD (NCT04023552) }\end{array}$ \\
\hline Pemafibrate & PROMINENT [47] & $\begin{array}{l}\text { The primary objective of the study is to determine whether pemafibrate administered } \\
\text { twice daily will delay the time to first occurrence of any component of the clinical } \\
\text { composite endpoint of non-fatal myocardial infarction, non-fatal ischemic stroke, } \\
\text { hospitalization for unstable angina requiring unplanned coronary revascularization } \\
\text { or cardiovascular death (NCT03071692) }\end{array}$ \\
\hline
\end{tabular}


angiopoietin-like protein 3 (ANGPTL3) [57]. ANGPTL3 inhibits hydrolysis of TGs by lipoprotein lipase (LPL) and loss of function mutations in the ANGPTL3 gene are associated with protection against ASCVD [40,58]. Treatment with evinacumab, a fully human monoclonal antibody directed to ANGPTL3, led to reduced plasma TG and surprisingly LDL$\mathrm{C}$ levels in humans [59]. Of particular interest has been the observation that inhibition of ANGPTL3 significantly reduced LDL-C in homozygous FH (HoFH) patients [60]. In the earlier series, in nine HoFH patients, including two LDL receptor gene $(L D L R)$ null/null homozygotes, the mean LDL$\mathrm{C}$ reduction after 4 weeks on evinacumab $(250 \mathrm{mg}$ sc at baseline and $15 \mathrm{mg} / \mathrm{kg}$ iv at week 2) was $49 \pm 23 \%$. These patients were already on optimal treatment with statins, ezetimibe, lomitapide, and PCSK9 monoclonal antibodies. The two null/null homozygotes showed a modest response. More recently, a larger study (ELIPSE trial) on 65 homozygotes showed that iv infusion of evinacumab $(15 \mathrm{mg} / \mathrm{kg})$, every 4 weeks, followed for 24 weeks reduced LDL-C by $47.1 \%$ compared with a $1.9 \%$ increase in the placebo group (between group mean difference of $-49 \%$ ) [61]. Responses were robust even in patients with $L D L R$ null/null variants $(-43.4 \%$ vs. $+16.2 \%$ in placebo). No significant differences in adverse events between those receiving evinacumab or placebo were reported.

The superiority of evinacumab administered either sc or iv compared to placebo was also seen in patients with refractory hypercholesterolemia. Among 272 patients with LDL-C levels of $150 \pm 80.2 \mathrm{mg} / \mathrm{dL}$ despite use of other lipid-lowering medications including monoclonal PCSK9 inhibitors, evinacumab significantly reduced LDL-C by more than $50 \%$ at the maximum dose $(450 \mathrm{mg} /$ weekly sc regimen and $15 \mathrm{mg} / \mathrm{Kg}$ every 4 weeks iv regimen) [62]. The pharmacokinetic profile of both regimens seems not to differ between ethnicities at least in the Caucasian and in the Japanese [63].

\section{Lp(a)-Novelties in the Era of RNA-based Therapies}

Despite the association between $\operatorname{Lp}(\mathrm{a})$ elevations and coronary artery disease risk has emerged from both epidemiological and genetic studies [64-66], a pharmacological approach able to lower $\mathrm{Lp}(\mathrm{a})$ levels to the extent required to potentially achieve a CV benefit in patients with progressive ASCVD and high plasma $\mathrm{Lp}(\mathrm{a})$ is still missing (reviewed in [67]). Available lipid-lowering therapies have little value for $L p(a)$ reduction. Aside from statins that could raise $\mathrm{Lp}$ (a) blood concentrations [68, 69], PCSK9 inhibitors reduce Lp(a) levels by $25-30 \%$ [70] and there is evidence that reduction of $\mathrm{Lp}(\mathrm{a})$ elicited by these drugs might contribute to an improved prognosis in coronary disease patients [71]. Finally, for patients with progressive ASCVD and high plasma Lp(a), a possible approach sometimes used is lipoprotein apheresis [72]. Although with the limitation of not being a randomized trial, the prospective study by Roeseler et al. [73] reported a significant CV benefit with different apheresis techniques in patients with hyperlipoproteinemia(a), an observation reported also in the German Lipoprotein Apheresis Registry [74].

In view of the limited activity of generally available lipidlowering drugs and the ongoing progress in antisense-DNA based therapies, the most recent phase $2 \mathrm{~b}$ trial with an apo(a) antisense oligonucleotide (ASO) tested an APO(a)Lrx conjugated with GalNac in patients with pre-existing CVD and baseline $\mathrm{Lp}(\mathrm{a})>60 \mathrm{mg} / \mathrm{dL}$. The active compound reduced dramatically, in a dose-dependent manner, the levels of $\mathrm{Lp}$ (a): mean percentage decreases were $35 \%$ at $20 \mathrm{mg}$ Q4W, $56 \%$ at $40 \mathrm{mg} \mathrm{Q} 4 \mathrm{~W}, 58 \%$ at $20 \mathrm{mg} \mathrm{Q} 2 \mathrm{~W}, 72 \%$ at $60 \mathrm{mg}$ $\mathrm{Q} 4 \mathrm{~W}$, and $80 \%$ at $20 \mathrm{mg} \mathrm{QW}$. These changes allowed $97.7 \%$ of patients allocated to $20 \mathrm{mg}$ QW to reach $\mathrm{Lp}$ (a) levels $\leq 50 \mathrm{mg} / \mathrm{dL}$. APO(a)Lrx was well tolerated and did not lead to changes in platelet counts, liver and renal functions, with no signs of influenza-like symptoms. The most common associated adverse reaction was erythema (26\%) and only one patient discontinued treatment because of an injection site reaction [75].

Very recently, the activity of a new GalNAc-conjugated small interfering RNA targeting mRNA transcribed from the LPA gene (Amg890) has been reported in Abstract form. In this phase 1 trial (NCT03626662), in 64 patients with elevated Lp(a), a single-dose treatment with AMG 890 was welltolerated and significantly reduced $L p(a)$ with observed maximal percent reductions of $>90 \%$ [76]. A phase 2 study is ongoing (NCT04270760) with an estimated enrollment of 240 patients with ASCVD and Lp(a) $>150 \mathrm{mg} / \mathrm{dL}$. Completion is expected by April 2023.

\section{Triglyceride Reduction: New Options and Effectiveness}

Lowering of TGs is today still best accomplished by peroxisomal proliferator-associated receptor $(\alpha, \beta$, and $\gamma)$ activation. Fibrates, the most effective activators of the PPAR $\alpha$ system, generally have a mixed $\operatorname{PPAR} \alpha, \beta$ activity [77]. PPARs belong to the nuclear hormone receptor superfamily and, by binding to PPAR-response regulatory elements (PPRE) heterodimerize with the retinoid X receptor (RXR) thus modulating genes involved in adipogenesis, lipid metabolism, inflammation, and control/maintenance of metabolic homeostasis [78, 79]. Among fibrates, fenofibrate is mainly active on PPAR $\alpha$ whereas bezafibrate acts on PPAR $\alpha-\beta / \delta$, glitazones acting instead on PPAR $\gamma$. By this mechanism, fibrates down-regulate apolipoprotein-CIII (apo-CIII) while stimulating the lipoprotein lipase gene expression thus affecting TG metabolism [80]. 
Among PPARs, PPAR $\alpha$ (also called NR1C1) is activated mainly under energy deprivation, in particular during fasting [81], PPAR $\alpha$-mediated fatty acid catabolism is crucial for the synthesis of metabolites to be used as energy sources to other tissues such as ketone bodies in the brain [82]. In addition to activating a number of genes in the FA $\beta$-oxidation pathway, e.g., carnitine palmitoyl transferase $1 \mathrm{~A}$ and $2, \operatorname{PPAR} \alpha$ also exerts an anti-inflammatory activity in mouse models, although contrasting data have been reported [83].

\section{Pemafibrate}

Currently, there is growing interest in the selective activation of PPAR $\alpha$. Newly available $\operatorname{PPAR} \alpha$ agonists may provide an advancement, since older fibrates have a relatively weak activity and display limited efficacy due to elevation of transaminase, homocysteine, and creatinine with consequent, although rare, myopathy. The increased selectivity of PPAR $\alpha$ is best exemplified by pemafibrate (previously known as K877), >2,000-fold more selective for PPAR $\alpha$ vs either PPAR $\gamma$ or $\delta[84,85]$. Clinical evaluation confirmed the extremely low active doses $(0.1-0.2 \mathrm{mg}$ bid) compared to fenofibrate (106.6 mg qd). A comparative trial over 24 weeks showed TG reductions of $46 \%$ for pemafibrate vs $-39.7 \%$ for fenofibrate [86]. This finding was confirmed in a number of further trials, also indicating that adverse events were less frequent vs fenofibrate $200 \mathrm{mg} /$ day [87]. The use of pemafibrate was also proposed for the handling of residual dyslipidemia for patients with TG>300 mg/dL on statins. Regardless of statin background combination therapy, pemafibrate $0.2-0.4 \mathrm{mg} /$ day led to $\mathrm{TG}$ reductions of about $50 \%$ from baseline [88]. These very positive findings have led to the planning of the PROMINENT (Pemafibrate to Reduce Cardiovascular Outcomes by Reducing Triglycerides in Patients with Diabetes) trial involving high ASCVD risk patients with in use of T2DM on statin therapy and who persist with atherogenic dyslipidemia. The primary end-point is the time of occurrence of the first non-fatal MI, ischemic stroke, unstable angina or coronary revascularization, and CV deaths [47]. Two studies in Europe and the USA are currently ongoing in patients with severe hypertriglyceridemia (Table 2).

\section{Omega-3}

The latest development in the treatment in hypertriglyceridemias has been the unexpected CV effectiveness of FA of the n-3 series (i.e., with multiple double bonds, the first being in the $n-3$ position from the terminal methyl group). These omega-3s act as "fraudulent fatty acids" [89], i.e., they, somewhat similar to drugs with the FA-like structure, particularly fibrates, do not follow the liver metabolic handling by the classical fatty acetyl CoA oxidative mechanism with carnitine-mediated transport to mitochondria [90]. They exert, instead, a moderate stimulation of the $\operatorname{PPAR} \alpha$-mediated pathway, although peroxisomal proliferation is less extensive than in the case of fibrates [91]. Clinical trials in patients given elevated daily doses of omega- 3 in the form of $\mathrm{TG}$ or more recently of ethyl esters of eicosapentaenoic (EPA) or docosaexaenoic (DHA) acid, as well as with novel formulations of separated fatty acids, repeatedly confirmed an effective activity in TG reduction, particularly in patients with diabetes [92]. A general review on the mechanisms of omega-3 involves targeting of characteristics of the metabolic syndrome, i.e., raised adipocyte differentiation, reduced lipolysis and lipogenesis and, more recently, reduced inflammatory changes in the adipose tissue, characteristic of obesity [93]. Recent evidence has, however, provided exciting observations from a clinical trial on high dose EPA. The REDUCE-IT trial involved 8,179 participants with high $\mathrm{CV}$ risk $(71 \%$ with established $\mathrm{CV}$ disease and 58\% with T2DM). These had essentially normal LDL$\mathrm{C}$ upon optimal statin treatment $(75 \mathrm{mg} / \mathrm{dL})$ whereas mean TG levels were moderately elevated (median value $216 \mathrm{mg}$ $/ \mathrm{dL}$ ). Patients receiving $4 \mathrm{~g}$ of icosapent ethyl per day (2 $\mathrm{g}$ bid with meals) vs placebo for a median follow-up of 4.9 years had an absolute between group difference in primary $\mathrm{CV}$ endpoints of $4.8 \%$ vs placebo with a number needed to treat of 21 [94]. Interestingly, a subsequent evaluation of the trial reported a significant decrement in the first and total CV deaths [95]: total primary endpoint events (CV death, nonfatal myocardial infarction, nonfatal stroke, coronary revascularization, or hospitalization for unstable angina) were decreased by $30 \%$ and total key secondary endpoint events (cardiovascular death, nonfatal myocardial infarction, or nonfatal stroke) by $28 \%$. Findings of the REDUCE-IT trial indicate that $\mathrm{TG}$ reduction (e.g., $-18.3 \%$ fall from baseline to 1 year) may be an important target of therapy, although possibly not all the benefits reported in the trial are explained by TG lowering. This tentative conclusion is supported by the recently reported EVAPORATE (Effect of Vascepa on Improving Coronary Atherosclerosis in People With High Triglycerides Taking Statin Therapy) trial in 80 coronary artery disease patients. They were allocated into two groups given a similar dose of EPA as in the REDUCE-IT trial or a placebo and followed for 18 months. Coronary computed tomographic scans showed that icosapent ethyl was superior to placebo in reducing plaque volume (primary endpoint) by $17 \%$, fibrofatty and fibrous plaques by $-34 \%$ and by $-20 \%$, respectively, whereas dense calcium did not change between groups [96].

Differently from the icosapent ethyl formulation, daily administration of $4 \mathrm{~g}$ of the carboxylic acid formulation of EPA and DHA, in patients with hypertriglyceridemia $(\geq 240 \mathrm{mg} /$ $\mathrm{dL})$ and or diabetes $(70 \%)$ resulted in neutral effects on $\mathrm{CV}$ 
Table 2 Ongoing or recently completed studies involving inhibition of agents reducing triglyceride-rich lipoproteins

\begin{tabular}{|c|c|c|}
\hline & Trial & Description \\
\hline Pemafibrate & $\begin{array}{l}\text { NCT03011450 (phase 3, in Europe) and } \\
\text { NCT03001817 (phase 3, in US) }\end{array}$ & $\begin{array}{l}\text { Study to evaluate the efficacy and safety of K-877 in adult patients with fasting high } \\
\text { triglyceride levels and mild or moderate renal impairment }\end{array}$ \\
\hline \multirow{3}{*}{$\begin{array}{l}\text { Evinacumab } \\
\text { (mAb against } \\
\text { ANGPTL3) }\end{array}$} & NCT04233918 (phase 3) & $\begin{array}{l}\text { Evaluating the efficacy and safety of evinacumab in pediatric patients with } \\
\text { homozygous familial hypercholesterolemia }\end{array}$ \\
\hline & NCT03452228 (phase 2) & $\begin{array}{l}\text { Safety and efficacy following repeat-dose of evinacumab (Anti-ANGPTL3) in } \\
\text { patients with severe hypertriglyceridemia (sHTG) at risk for acute pancreatitis }\end{array}$ \\
\hline & NCT03409744 (phase 3) & $\begin{array}{l}\text { Evaluate the long-term safety and efficacy of evinacumab in patients with } \\
\text { homozygous familial hypercholesterolemia }\end{array}$ \\
\hline \multirow{2}{*}{$\begin{array}{l}\text { Vupanorsen } \\
\quad\left(\text { ANGPTL3-L } \mathrm{L}_{\mathrm{Rx}}\right)\end{array}$} & NCT04516291 (phase 2) & A dose-ranging study with vupanorsen (TRANSLATE-TIMI 70) \\
\hline & NCT04459767 (phase 1) & $\begin{array}{l}\text { Investigation of safety, tolerability, pharmacokinetics and pharmacodynamics of } \\
\text { single doses of vupanorsen in Japanese healthy adult participants with elevated } \\
\text { triglycerides }\end{array}$ \\
\hline $\begin{array}{l}\text { ARO-ANG3 (silencing } \\
\text { RNA) }\end{array}$ & NCT03747224 (phase 1) & Study of ARO-ANG3 in healthy volunteers and in dyslipidemic patients \\
\hline \multirow[t]{2}{*}{ AKCEA-APOCIII-L ${ }_{\mathrm{Rx}}$} & NCT04568434 (phase 3) & $\begin{array}{l}\text { A study of administered to patients with familial chylomicronemia syndrome (FCS) } \\
\text { (BALANCE) }\end{array}$ \\
\hline & NCT03385239 (phase 2) & $\begin{array}{l}\text { Study of ISIS } 678354 \text { (AKCEA-APOCIII-LRx) in patients with } \\
\text { hypertriglyceridemia and established cardiovascular disease (CVD) }\end{array}$ \\
\hline $\begin{array}{l}\text { ARO-APOC3 } \\
\text { (silencing RNA) }\end{array}$ & NCT03783377 (phase 1) & $\begin{array}{l}\text { Study of ARO-APOC } 3 \text { in healthy volunteers, hypertriglyceridemic patients and } \\
\text { patients with familial chylomicronemia syndrome (FCS) }\end{array}$ \\
\hline
\end{tabular}

prevention compared to corn oil (placebo). Despite a $-20 \%$ reduction in $\mathrm{TG}$ and hsCRP, the HR for MACE (a composite of $\mathrm{CV}$ death, nonfatal MI, nonfatal stroke, coronary revascularization, or unstable angina requiring hospitalization) was 0.99 (95\%CI 0.90-1.09). The STRENGTH (The Long-Term Outcomes Study to Assess Statin Residual Risk with Epanova in High Cardiovascular Risk Patients with Hypertriglyceridemia), recruiting 13,078 patients, was halted prematurely when it became apparent that the probability of clinical benefit was likely to be low. An increased rate of newonset atrial fibrillation (HR 1.69, 95\%CI 1.29-2.21) and of gastrointestinal adverse events [97] was observed. Compared to the REDUCE-IT study, the achieved EPA levels in plasma and red blood cells were lower but it is uncertain whether these differences would be sufficient to explain the impact on MACE. The question as to whether possible deleterious effects of DHA in STRENGTH or the use of mineral oil in REDUCE-IT, with the potential of the latter to raise LDL-C and hsCRP, could be responsible for the different findings remains to be determined [98] although data from comparative trials suggest no significant impact of mineral oil on $\mathrm{CV}$ outcomes [99].

\section{ANGPTL3 and Apo C-III Inhibition}

In addition to evinacumab, antisense oligonucleotides (ASOs) targeting ANGPTL3 messenger RNA are under clinical evaluation. ANGPTL3- $\mathrm{L}_{\mathrm{Rx}}$, a second-generation ASO drug targeting ANGPTL3 mRNA, has a covalent linkage with the
GalNAc cluster, conferring high affinity for the hepatocytespecific asialoglycoprotein receptor (reviewed in [40]).

A phase 1 trial aimed at testing the safety, pharmacokinetics, and pharmacodynamics of single ascending doses and multiple ascending doses of ANGPTL3-L $\mathrm{L}_{\mathrm{RX}}$ (vupanorsen) in healthy volunteers showed that this last was the regimen to be used. Once a week injection for 6 weeks of active compound reduced, at day 43, the circulating levels of ANGPTL3 from baseline by $46.6 \%(10 \mathrm{mg}), 72.5 \%$ (20 mg), 81.3\% (40 $\mathrm{mg})$, and $84.5 \%(60 \mathrm{mg})$. Compared to placebo $(0.9 \%$ sterile saline s.c.), ANGPTL3-L $\mathrm{RX}_{\mathrm{RX}}$ lowered TG (from -33.2 to $-63.1 \%$ ), LDL-C (from -1.3 to $-32.9 \%$ ), VLDL-C (from -27.9 to $-60 \%$ ), non-HDL-C (from -10 to $-36.6 \%$ ), apoB (from -3.4 to $-25.7 \%$ ), and apolipoprotein (apo)C-III (from -18.9 to $-58.8 \%$ ). No clinical signs of prothrombotic effects, bleeding episodes, and significant decreases in platelet counts and liver or renal function damages were found ([100]).

In a recent phase 2 trial, enrolling 105 patients with median TG levels of $252 \mathrm{mg} / \mathrm{dL}$ and T2DM, vupanorsen reduced ANGPTL3 by 41\% (40 mg Q4W), 59\% (80 mg Q4W), and $56 \%$ (20 mg QW) leading to a dramatic reduction in TG levels, $-36 \%$ (40 mg Q4W), -53\% (80 mg Q4W), and -47\% (20 mg QW). Six months of treatment allowed most of the patients to reach TG levels < $150 \mathrm{mg} / \mathrm{dL}: 35 \%$ (40 mg Q4W), 58\% (80 mg Q4W), and 39\% (20 mg QW). At the dose of $80 \mathrm{mg}$ Q4W, ANGPTL3 was reduced by $62 \%$, apoC-III by $58 \%$, remnant cholesterol (and VLDL-C) by $38 \%$, non-HDL-C by $18 \%$, TC by $19 \%$, apoB by $9 \%$, and HDL-C by $24 \%$. Changes in LDL-C 
$(-12 \%)$ were found only in patients given the dose of $20 \mathrm{mg}$ QW. The most frequent adverse effects were injection-site pruritus and erythema, whereas no one experienced a confirmed platelet count $<100,000 / \mathrm{mm}^{3}[101 \cdot \bullet]$.

Besides ANGPTL3, another recently approached target for the treatment of severe hypertriglyceridemia is provided by inhibitors of apo C-III, a multifaceted protein in cardiometabolic disease [102]. Apo C-III is an inhibitor of LPL and has been recently identified as a risk factor for CV disease [103, 104]. Apo C-III is a small molecule with a molecular weight of $8.8 \mathrm{kDa}$ and 79 amino-acids, rapidly exchanged postprandially between lipoproteins [105]. Indeed, all lipoproteins may contain ApoC-III, although this apoprotein is mainly represented in chylomicrons, VLDL, their remnants, and HDL. The clinical observation of apo C-III mutations with significant loss-of-function and associated with low TGs and elevated HDL has been reported in a number of studies [106]. The lead investigators described a potential therapeutic approach to hypertriglyceridemia based on an inhibited activity of apo C-III (reviewed in [107]).

At present, the only reported effective strategy is by administration of an antisense oligonucleotide, although monoclonal antibodies STT505 and STT5058 seemed to lower apo C-III levels and promote clearance of TG-rich lipoproteins in mice [108].

The antisense inhibition was first evaluated by Gaudet et al. in patients with triglyceridemia between 350 and $2,000 \mathrm{mg} / \mathrm{dL}$ on stable fibrate therapy. Volanesorsen at doses from 100 to $300 \mathrm{mg}$ once weekly for 13 weeks led to dose-dependent reductions of apoC-III (from -40 to $-79.6 \%$ ) concomitant with dramatic TG reductions (from 31.3 to $70.9 \%$ ) [109]. A larger study was conducted on 66 patients with familial chylomicronemia syndrome (FCS) treated for 52 weeks. Volanesorsen dramatically reduced apoC-III levels by $84 \%$ and mean TG by $77 \%$, allowing after 3 months $77 \%$ of the patients to achieve TG levels $\leq 750 \mathrm{mg} / \mathrm{dL}$. However, 14 patients given volanesorsen did not terminate the trial due to platelet count reductions [110]. In spite of this drawback, the European Medical Agency (EMA) considered positively the benefit: risk ratio thus authorizing volanesorsen for the treatment of FCS. A recent meta-analysis of the available phase 2 and phase 3 clinical studies reported that volenesorsen significantly reduced VLDL-C $(-73 \%)$, TG $(-68 \%)$, ApoCIII $(-74 \%)$, and raised HDL $(+40 \%)$ and LDL-C $(+47 \%$, $\mathrm{p}=0.057)$. Specifically, looking at LDL-C, it is worth mentioning that although in the APPROACH study the rise in LDL-C was $+136 \%$, the basal LDL-C levels were very low $28 \pm 19 \mathrm{mg} / \mathrm{dL}$ to become $61 \pm 39 \mathrm{mg} / \mathrm{dL}$, still remaining in the normal range [110]. Overall, the increment in LDL$\mathrm{C}$ may be consequent to an enhanced conversion of VLDL to LDL or due to changes in the secretion and catabolism of the LDL particles, although changes in CETP activity cannot be excluded [111].

Injection of volanesorsen was associated with a significantly higher risk of injection site reactions $(\mathrm{OR}=32.89,95 \% \mathrm{CI}=$ 7.97-135.74) when compared to placebo [112].

Recently, a new GalNac-conjugated APOCIII- $\mathrm{L}_{\mathrm{Rx}}$ was tested in a dose-escalation Phase 1/2a study in healthy

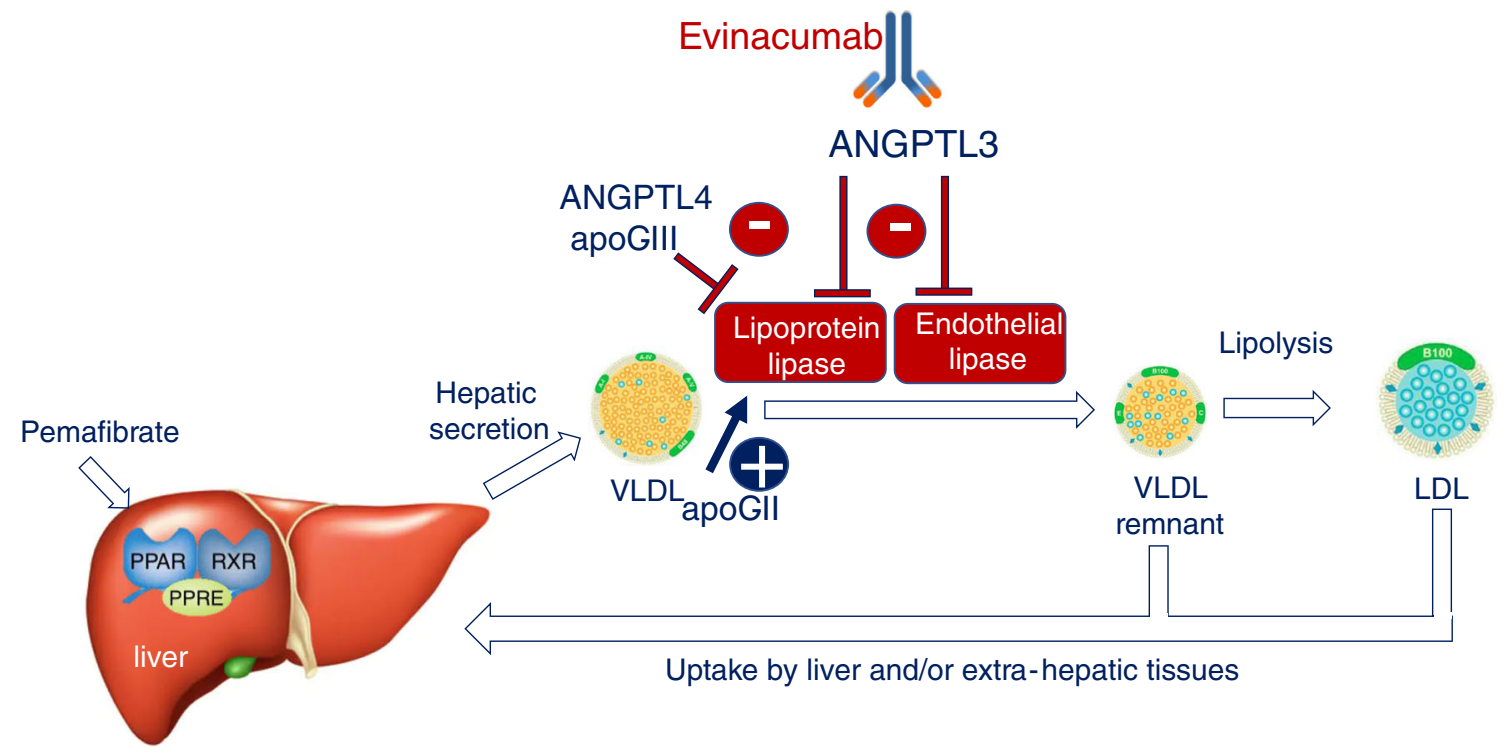

Fig. 2 Molecular mechanism of ANGPTL3 inhibition. ANGPTL3 inhibits both the lipoprotein and endothelial lipases and thus the conversion of VLDL into LDL. A similar effect is determined by ANGPTL4 and apoC-III, while apoC-II is a coactivator of lipoprotein lipase. The monoclonal antibody evinacumab binds and inhibits the ANGPTL3 generating VLDL remnant particles that are efficiently removed from the circulation. Thus, ANGPTL3 inhibition may lower LDL-C by limiting LDL particle production and endothelial lipase could be a key mediator of this novel pathway. ANGPTL, angiopoietinlike; apo, apolipoprotein; LDL, low-density lipoprotein; VLDL, very-low density lipoprotein. Adapted with permission of Elsevier [40]. 
volunteers. A large improvement in the atherogenic lipid profile was detected both following a single-dose- or a multidose-regimen. This last choice led to median reductions of apoC-III by $66 \%$ (15 mg QW4), 84\% (30 mg QW4), and by $89 \%$ (60 mg QW4) and of TG by $59 \%, 73 \%$, and $66 \%$, respectively. No flu-like reactions, platelet count reductions, liver, or renal safety signals were reported $[113,114]$.

\section{Conclusions}

The considerable progress in developing newer drugs and strategies for the management of hyperlipidemias will probably lead to considerable improvement in the clinical practice in the near future. New agents are now taking optimal care of $\mathrm{FH}$, even of the homozygous phenotype both in adults and pediatric individuals $[115,116]$. In this context, the enigmatic activity of evinacumab, an antagonist of ANGPTL3, to ameliorate LDL-C in HoFH patients may become of interest if statins, cholesterol-absorption inhibitors, or PCSK9 inhibitors would not be able to lower LDL-C to a sufficient degree or have unacceptable side effects. Specifically, the effect of evinacumab on extremely elevated LDL-C levels has been partly clarified by two different groups, both indicating that endothelial lipase (EL) may mediate the LDLR independent effect of ANGPTL3 inhibition. Adam et al. [117] reported that in the absence of EL, no significant LDL-C reduction is observed. In line with this evidence, $\mathrm{Wu}$ et al. [118] noted that in EL knock-out mice, compared to wildtype ones, ANGPTL3 inhibition reduced LDL-C only in the latter. Although a clear mechanism linking ANGPTL3 inhibition and LDL-C reduction remains unsolved as yet, the most reliable hypotheses report an EL-mediated clearance of LDL precursors (VLDL and IDL) or an EL-accelerated LDL catabolism (Fig. 2).

The importance of reducing LDL-C has been further underscored by a recent prospective study on 4958 asymptomatic adults evaluating the relationship among the incidence of ASCVD event risk, the cumulative exposure to LDL-C, and the time course of LDL-C accumulation [119]. However, moving to real-life, there is a gap between clinical guidelines and clinical practice, an evidence underscored by the recent DA VINCI study, an 18 country, cross-sectional, observational study of patients prescribed lipid-lowering therapies for primary and secondary care across Europe $[120 \bullet \bullet$.

The recent 2019 European guidelines for the management of hypercholesterolemia have added PCSK9 inhibitors to the therapeutic armamentarium to achieve the LDL-C goals. Besides monoclonal antibodies, a new biosynthetic drug is approaching, inclisiran. However, despite the powerful effect on LDL-C lowering, a recent cost-effectiveness analysis from the Australian healthcare perspective showed that the cost of inclisiran would have to be $60 \%$ lower than that of evolocumab [121]. This observation is of high interest considering that the 2019 ESC/EAS guidelines rendered half of all post-acute coronary syndrome patients potentially eligible for PCSK9 inhibitors [122]. Thus, in order to achieve the LDL-C target levels in high risk ASCVD patients, adding new drugs like bempedoic acid, more cost-effective but less potent than PCSK9 inhibitors, may be envisioned as second- or third-line agents, similar to ezetimibe and bile acid sequestrants (reviewed in [84]).

Notwithstanding, major challenges are forthcoming in the case of Lp(a), a still not fully understood CV risk marker. Two generations of ASOs have been presented, apparently allowing to reduce $\mathrm{Lp}$ (a) by up to $90 \%$. In this special case, long term-controlled risk evaluations will also allow to clarify the independent risk role of elevated $\mathrm{Lp}(\mathrm{a})$.

Since the pathophysiology of atherosclerosis is a continuum from early to advanced vascular disease with lipoproteins playing a pillar role, it is worth mentioning that in ASCVD patients carrying the traits of metabolic syndrome, a considerable residual risk remains. Considering that the most recent approaches to manage severe forms of hypertriglyceridemia by means of the antagonism of apo C-III or of ANGPLT3 are far from to be clinically available, the use of icosapent ethyl or pemafibrate [123] becomes of high interest. In individuals with high levels of TG, icosapent ethyl was superior to placebo to reduce not only the first CVD event but also the subsequent ones [124]. This evidence is of extreme importance considering that CVD risk is eight-fold higher among those with ASCVD than those without it [125]. However, considering that the global market for omega-3 fatty acids has reached $\$ 4.1$ billion and is expected to double by 2025 , the neutral effects reported in the STRENGTH and VITAL (Vitamin D and Omega-3 Trial) studies should be a reminder that the widespread use of over-the-counter mixed omega-3 products lacks evidence for clinical utility [126].

Acknowledgements RDS is recipient of a scholarship from the Conselho Nacional de Pesquisa e Desenvolvimento Tecnológico, Brazil, (CNPq) \#303734/2018-3.

Funding Open access funding provided by Università degli Studi di Milano within the CRUI-CARE Agreement.

\section{Declarations}

Human and Animal Rights and Informed Consent This article does not contain any studies with human or animal subjects performed by any of the authors.

Conflict of Interest Raul D. Santos has received honoraria related to consulting, research, and/or speaker activities from: Abbott, Ache, Amgen, Astra Zeneca, Esperion, EMS, GETZ Pharma, Kowa, Libbs, Novartis, Novo-Nordisk, Merck, MSD, Pfizer, PTC Therapeutics, and 
Sanofi/Regeneron. Alberto Corsini has received honoraria from Amgen, Astra Zeneca, Daiichi Sankyo. MR, NF, and CRS declare that they have no conflict of interest.

Open Access This article is licensed under a Creative Commons Attribution 4.0 International License, which permits use, sharing, adaptation, distribution and reproduction in any medium or format, as long as you give appropriate credit to the original author(s) and the source, provide a link to the Creative Commons licence, and indicate if changes were made. The images or other third party material in this article are included in the article's Creative Commons licence, unless indicated otherwise in a credit line to the material. If material is not included in the article's Creative Commons licence and your intended use is not permitted by statutory regulation or exceeds the permitted use, you will need to obtain permission directly from the copyright holder. To view a copy of this licence, visit http://creativecommons.org/licenses/by/4.0/.

\section{References}

Papers of particular interest, published recently, have been highlighted as:

- Of importance

•- Of major importance

1. Goyal A, Cho L. Preventive cardiology and risk assessment: Beyond LDL. Curr Atheroscler Rep. 2020;22(10):56.

2. Yusuf S, Hawken S, Ounpuu S, et al. Effect of potentially modifiable risk factors associated with myocardial infarction in 52 countries (the INTERHEART study): case-control study. Lancet. 2004;364(9438):937-52.

3. Ference BA, Ginsberg HN, Graham I, Ray KK, Packard CJ, Bruckert E, et al. Low-density lipoproteins cause atherosclerotic cardiovascular disease. 1. Evidence from genetic, epidemiologic, and clinical studies. A consensus statement from the European Atherosclerosis Society Consensus Panel. Eur Heart J. 2017;38(32):2459-72.

4. Boren J, Chapman MJ, Krauss RM, et al. Low-density lipoproteins cause atherosclerotic cardiovascular disease: pathophysiological, genetic, and therapeutic insights: a consensus statement from the European Atherosclerosis Society Consensus Panel. Eur Heart J. 2020;41(24):2313-30.

5. Nordestgaard BG, Benn M, Schnohr P, Tybjaerg-Hansen A. Nonfasting triglycerides and risk of myocardial infarction, ischemic heart disease, and death in men and women. JAMA. 2007;298(3):299-308.

6. Ference BA, Kastelein JJP, Ray KK, Ginsberg HN, Chapman MJ, Packard CJ, et al. Association of triglyceride-lowering LPL variants and LDL-C-lowering LDLR variants with risk of coronary heart disease. JAMA. 2019;321(4):364-73.

7. Grundy SM, Stone NJ, Bailey AL, Beam C, Birtcher KK, Blumenthal RS, et al. 2018 AHA/ACC/AACVPR/AAPA/ABC/ ACPM/ADA/AGS/APhA/ASPC/NLA/PCNA Guideline on the management of blood cholesterol: a report of the American College of Cardiology/American Heart Association Task Force on Clinical Practice Guidelines. Circulation. 2019;139(25): e1082-143.

8. Authors/Task Force M, Guidelines ESCCfP, Societies ESCNC. 2019 ESC/EAS guidelines for the management of dyslipidaemias: lipid modification to reduce cardiovascular risk. Atherosclerosis. 2019;290:140-205.
9. Matsuura Y, Kanter JE, Bornfeldt KE. Highlighting residual atherosclerotic cardiovascular disease risk. Arterioscler Thromb Vasc Biol. 2019;39(1):e1-9.

10. Reiner Z. Hypertriglyceridaemia and risk of coronary artery disease. Nat Rev Cardiol. 2017;14(7):401-11.

11. Xiao C, Dash S, Morgantini C, Hegele RA, Lewis GF. Pharmacological targeting of the atherogenic dyslipidemia complex: the next frontier in CVD prevention beyond lowering LDL cholesterol. Diabetes. 2016;65(7):1767-78.

12. Nelson AJ, Navar AM, Mulder H, Wojdyla D, Philip S, Granowitz C, et al. Association between triglycerides and residual cardiovascular risk in patients with type 2 diabetes mellitus and established cardiovascular disease (from the Bypass Angioplasty Revascularization Investigation 2 Diabetes [BARI 2D] Trial). Am J Cardiol. 2020;132:36-43.

13. Sirtori CR, Ruscica M, Calabresi L, Chiesa G, Giovannoni R, Badimon JJ. HDL therapy today: from atherosclerosis, to stent compatibility to heart failure. Ann Med. 2019;51(7-8):345-59.

14. Zheng KH, Kaiser Y, van Olden CC, Santos RD, Dasseux JL, Genest J, et al. No benefit of HDL mimetic CER-001 on carotid atherosclerosis in patients with genetically determined very low HDL levels. Atherosclerosis. 2020;311:13-9.

15. Patel AP, Wang M, Pirruccello JP, et al. Lp(a) (Lipoprotein[a]) Concentrations and incident atherosclerotic cardiovascular disease: new insights from a large national biobank. Arterioscler Thromb Vasc Biol. 2021;41(1):465-74.

16. Schnitzler JG, Hoogeveen RM, Ali L, Prange KHM, Waissi F, van Weeghel M, et al. Atherogenic lipoprotein(a) increases vascular glycolysis, thereby facilitating inflammation and leukocyte extravasation. Circ Res. 2020;126(10):1346-59.

17. Tsimikas S. A test in context: lipoprotein(a): diagnosis, prognosis, controversies, and emerging therapies. J Am Coll Cardiol. 2017;69(6):692-711.

18. Sirtori CR. The pharmacology of statins. Pharmacol Res. 2014;88: 3-11.

19. Amarenco P, Kim JS, Labreuche J, Charles H, Abtan J, Bejot Y, Cabrejo L, Cha JK, Ducrocq G, Giroud M, Guidoux C, Hobeanu C, Kim YJ, Lapergue B, Lavallee PC, Lee BC, Lee KB, Leys D, Mahagne MH, Meseguer E, Nighoghossian N, Pico F, Samson Y, Sibon I, Steg PG, Sung SM, Touboul PJ, Touze E, Varenne O, Vicaut E, Yelles N, Bruckert E. Treat stroke to target investigators. a comparison of two LDL cholesterol targets after ischemic stroke. N Engl J Med. 2020 Jan 2;382(1):9.

20. Ferri N, Grego MF, Corsini A, Ruscica M. Proprotein convertase subtilisin/kexin type 9: an update on the cardiovascular outcome studies. Eur Heart J Suppl. 2020;22(Suppl E):E64-7.

21. Sabatine MS, Giugliano RP, Keech AC, Honarpour N, Wiviott $\mathrm{SD}$, Murphy SA, et al. Evolocumab and clinical outcomes in patients with cardiovascular disease. N Engl J Med. 2017;376(18): 1713-22.

22. Sever P, Gouni-Berthold I, Keech A, et al. LDL-cholesterol lowering with evolocumab, and outcomes according to age and sex in patients in the FOURIER Trial. Eur J Prev Cardiol. 2020: 2047487320902750.

23. Sabatine MS, De Ferrari GM, Giugliano RP, et al. Clinical benefit of evolocumab by severity and extent of coronary artery disease: analysis from FOURIER. Circulation. 2018;138(8):756-66.

24. Bonaca MP, Nault P, Giugliano RP, Keech AC, Pineda AL, Kanevsky E, et al. Low-density lipoprotein cholesterol lowering with evolocumab and outcomes in patients with peripheral artery disease: insights from the FOURIER trial (Further Cardiovascular Outcomes Research With PCSK9 Inhibition in Subjects With Elevated Risk). Circulation. 2018;137(4):338-50.

25. Gencer B, Mach F, Murphy SA, et al. Efficacy of evolocumab on cardiovascular outcomes in patients with recent myocardial infarction: a prespecified secondary analysis from the FOURIER trial. 
JAMA Cardiol. 2020; The Authors provide evidence to aggressively lower low-density lipoprotein cholesterol levels in very high-risk patients, such as those with a recent myocardial infarction.

26. Wiviott SD, Giugliano RP, Morrow DA, de Ferrari GM, Lewis BS, Huber K, et al. Effect of evolocumab on type and size of subsequent myocardial infarction: a prespecified analysis of the FOURIER randomized clinical trial. JAMA Cardiol. 2020;5(7): 787-93.

27. Sabatine MS, Leiter LA, Wiviott SD, Giugliano RP, Deedwania P, de Ferrari GM, et al. Cardiovascular safety and efficacy of the PCSK9 inhibitor evolocumab in patients with and without diabetes and the effect of evolocumab on glycaemia and risk of newonset diabetes: a prespecified analysis of the FOURIER randomised controlled trial. Lancet Diabetes Endocrinol. 2017;5(12):941-50.

28. Deedwania P, Murphy SA, Scheen A, et al. Efficacy and safety of PCSK9 inhibition with evolocumab in reducing cardiovascular events in patients with metabolic syndrome receiving statin therapy: secondary analysis from the FOURIER randomized clinical trial. JAMA Cardiol. $2021 \mathrm{Feb}$ 1;6(2):139-47.

29. Giugliano RP, Pedersen TR, Saver JL, et al. Stroke prevention with the PCSK9 (Proprotein Convertase Subtilisin-Kexin Type 9) inhibitor evolocumab added to statin in high-risk patients with stable atherosclerosis. Stroke. 2020;51(5):1546-54.

30. Sinnaeve PR, Schwartz GG, Wojdyla DM, Alings M, Bhatt DL, Bittner VA, et al. Effect of alirocumab on cardiovascular outcomes after acute coronary syndromes according to age: an ODYSSEY OUTCOMES trial analysis. Eur Heart J. 2020;41(24):2248-58.

31. Tunon J, Steg PG, Bhatt DL, et al. Effect of alirocumab on major adverse cardiovascular events according to renal function in patients with a recent acute coronary syndrome: prespecified analysis from the ODYSSEY OUTCOMES randomized clinical trial. Eur Heart J. 2020 Nov 7;41(42):4114-23.

32. Jukema JW, Zijlstra LE, Bhatt DL, Bittner VA, Diaz R, Drexel H, et al. Effect of alirocumab on stroke in ODYSSEY OUTCOMES. Circulation. 2019;140(25):2054-62.

33. Szarek M, Steg PG, DiCenso D, Bhatt DL, Bittner VA, Budaj A, et al. Alirocumab reduces total hospitalizations and increases days alive and out of hospital in the ODYSSEY OUTCOMES Trial. Circ Cardiovasc Qual Outcomes. 2019;12(11):e005858.

34. Marston NA, Kamanu FK, Nordio F, Gurmu Y, Roselli C, Sever PS, et al. Predicting benefit from evolocumab therapy in patients with atherosclerotic disease using a genetic risk score: results from the FOURIER Trial. Circulation. 2020;141(8):616-23.

35. Damask A, Steg PG, Schwartz GG, Szarek M, Hagström E, Badimon L, et al. Patients with high genome-wide polygenic risk scores for coronary artery disease may receive greater clinical benefit from alirocumab treatment in the ODYSSEY OUTCOMES trial. Circulation. 2020;141(8):624-36.

36. Marston NA, Gurmu Y, Melloni GEM, Bonaca M, Gencer B, Sever PS, et al. The effect of PCSK9 (proprotein convertase subtilisin/kexin type 9) inhibition on the risk of venous thromboembolism. Circulation. 2020;141(20):1600-7.

37. Ruscica M, Tokgozoglu L, Corsini A, Sirtori CR. PCSK9 inhibition and inflammation: a narrative review. Atherosclerosis. 2019;288:146-55.

38. Ruscica M, Corsini A, Ferri N, Banach M, Sirtori CR. Clinical approach to the inflammatory etiology of cardiovascular diseases. Pharmacol Res. 2020;159:104916.

39. Macchi C, Sirtori CR, Corsini A, Santos RD, Watts GF, Ruscica $M$. A new dawn for managing dyslipidemias: the era of rna-based therapies. Pharmacol Res. 2019;150:104413.

40. Ruscica M, Zimetti F, Adorni MP, Sirtori CR, Lupo MG, Ferri N. Pharmacological aspects of ANGPTL3 and ANGPTL4 inhibitors: new therapeutic approaches for the treatment of atherogenic dyslipidemia. Pharmacol Res. 2020;153:104653.

41. Brandts J, Ray KK. Small interfering RNA to proprotein convertase subtilisin/kexin type 9: transforming LDLcholesterol-lowering strategies. Curr Opin Lipidol. 2020;31(4): 182-6.

42. Sarett SM, Nelson CE, Duvall CL. Technologies for controlled, local delivery of siRNA. J Control Release. 2015;218:94-113.

43. Raal FJ, Kallend D, Ray KK, Turner T, Koenig W, Wright RS, et al. Inclisiran for the treatment of heterozygous familial hypercholesterolemia. N Engl J Med. 2020;382(16):1520-30.

44. Cordero A, Santos-Gallego CG, Facila L, et al. Estimation of the major cardiovascular events prevention with Inclisiran. Atherosclerosis. 2020;313:76-80.

45.•- Ray KK, Wright RS, Kallend D, et al. Two phase 3 trials of inclisiran in patients with elevated LDL cholesterol. N Engl J Med. 2020;382(16):1507-19 The Authors provided evidence of efficacy and safety of inclisirin in adults with heterozygous familial hypercholesterolemia. Inclisiran was superior to placebo in lowering levels of LDL cholesterol.

46. Nicholls S, Lincoff A, Bays $\mathrm{H}$, et al. Rationale and design of the CLEAR-outcomes trial: evaluating the effect of Bempedoic acid on cardiovascular events in patients with statin intolerance. Am Heart J. 2020.

47. Pradhan AD, Paynter NP, Everett BM, Glynn RJ, Amarenco P, Elam M, et al. Rationale and design of the Pemafibrate to Reduce Cardiovascular Outcomes by Reducing Triglycerides in Patients with Diabetes (PROMINENT) study. Am Heart J. 2018;206:8093.

48. Wright RS, Collins MG, Stoekenbroek RM, Robson R, Wijngaard PLJ, Landmesser U, et al. Effects of renal impairment on the pharmacokinetics, efficacy, and safety of inclisiran: an analysis of the ORION-7 and ORION-1 studies. Mayo Clin Proc. 2020;95(1):77-89.

49. Pinkosky SL, Newton RS, Day EA, Ford RJ, Lhotak S, Austin $\mathrm{RC}$, et al. Liver-specific ATP-citrate lyase inhibition by bempedoic acid decreases LDL-C and attenuates atherosclerosis. Nat Commun. 2016;7:13457.

50. Bilen O, Ballantyne CM. Bempedoic acid (ETC-1002): an investigational inhibitor of ATP citrate lyase. Curr Atheroscler Rep. 2016;18(10):61.

51. Bays HE, Banach M, Catapano AL, Duell PB, Gotto AM Jr, Laufs $\mathrm{U}$, et al. Bempedoic acid safety analysis: pooled data from four phase 3 clinical trials. J Clin Lipidol. 2020;14:649-659.e6.

52. Goldberg AC, Leiter LA, Stroes ESG, Baum SJ, Hanselman JC, Bloedon LAT, et al. Effect of bempedoic acid vs placebo added to maximally tolerated statins on low-density lipoprotein cholesterol in patients at high risk for cardiovascular disease: the CLEAR Wisdom Randomized Clinical Trial. JAMA. 2019;322(18): 1780-8.

53. Banach M, Duell PB, Gotto AM Jr, Laufs U, Leiter LA, Mancini GBJ, et al. Association of bempedoic acid administration with atherogenic lipid levels in phase 3 randomized clinical trials of patients with hypercholesterolemia. JAMA Cardiol. 2020;5:1124.

54. Ballantyne CM, Laufs U, Ray KK, Leiter LA, Bays HE, Goldberg $\mathrm{AC}$, et al. Bempedoic acid plus ezetimibe fixed-dose combination in patients with hypercholesterolemia and high CVD risk treated with maximally tolerated statin therapy. Eur J Prev Cardiol. 2020;27(6):593-603.

55. Khan MU, Khan MZ, Munir MB, Balla S, Khan SU. Metaanalysis of the safety and efficacy of bempedoic acid. Am J Cardiol. 2020;131:130-2.

56. Ference BA, Ray KK, Catapano AL, Ference TB, Burgess S, Neff DR, et al. Mendelian randomization study of ACLY and cardiovascular disease. N Engl J Med. 2019;380(11):1033-42. 
57. Gusarova V, Alexa CA, Wang Y, Rafique A, Kim JH, Buckler D, et al. ANGPTL3 blockade with a human monoclonal antibody reduces plasma lipids in dyslipidemic mice and monkeys. J Lipid Res. 2015;56(7):1308-17.

58. Arca M, D'Erasmo L, Minicocci I. Familial combined hypolipidemia: angiopoietin-like protein-3 deficiency. Curr Opin Lipidol. 2020;31(2):41-8.

59. Dewey FE, Gusarova V, Dunbar RL, O'Dushlaine C, Schurmann $\mathrm{C}$, Gottesman $\mathrm{O}$, et al. Genetic and pharmacologic inactivation of ANGPTL3 and cardiovascular disease. N Engl J Med. 2017;377(3):211-21.

60. Gaudet D, Gipe DA, Pordy R, Ahmad Z, Cuchel M, Shah PK, et al. ANGPTL3 inhibition in homozygous familial hypercholesterolemia. N Engl J Med. 2017;377(3):296-7.

61. Raal FJ, Rosenson RS, Reeskamp LF, Hovingh GK, Kastelein JJP, Rubba P, et al. Evinacumab for homozygous familial hypercholesterolemia. N Engl J Med. 2020;383(8):711-20.

62. Rosenson RS, Burgess LJ, Ebenbichler CF, Baum SJ, Stroes ESG, Ali S, et al. Evinacumab in patients with refractory hypercholesterolemia. N Engl J Med. 2020;383:2307-19.

63. Harada-Shiba M, Ali S, Gipe DA, Gasparino E, Son V, Zhang Y, et al. A randomized study investigating the safety, tolerability, and pharmacokinetics of evinacumab, an ANGPTL3 inhibitor, in healthy Japanese and Caucasian subjects. Atherosclerosis. 2020;314:33-40.

64. Emerging Risk Factors C, Erqou S, Kaptoge S, et al. Lipoprotein(a) concentration and the risk of coronary heart disease, stroke, and nonvascular mortality. JAMA. 2009;302(4): 412-23.

65. Saleheen D, Haycock PC, Zhao W, Rasheed A, Taleb A, Imran A, et al. Apolipoprotein(a) isoform size, lipoprotein(a) concentration, and coronary artery disease: a mendelian randomisation analysis. Lancet Diabetes Endocrinol. 2017;5(7):524-33.

66. Kamstrup PR, Tybjaerg-Hansen A, Steffensen R, Nordestgaard BG. Genetically elevated lipoprotein(a) and increased risk of myocardial infarction. JAMA. 2009;301(22):2331-9.

67. Greco MF, Sirtori CR, Corsini A, Ezhov M, Sampietro T, Ruscica M. Lipoprotein(a) lowering-from lipoprotein apheresis to antisense oligonucleotide approach. J Clin Med. 2020 Jul 3;9(7):2103.

68. Willeit P, Ridker PM, Nestel PJ, Simes J, Tonkin AM, Pedersen TR, et al. Baseline and on-statin treatment lipoprotein(a) levels for prediction of cardiovascular events: individual patient-data meta-analysis of statin outcome trials. Lancet. 2018;392(10155):1311-20.

69. Tsimikas S, Gordts P, Nora C, Yeang C, Witztum JL. Statin therapy increases lipoprotein(a) levels. Eur Heart J. 2020;41(24): 2275-84.

70. Ruscica M, Greco MF, Ferri N, Corsini A. Lipoprotein(a) and PCSK9 inhibition: clinical evidence. Eur Heart J Suppl. 2020;22(Suppl L):L53-6.

71. Szarek M, Bittner VA, Aylward P, Baccara-Dinet M, Bhatt DL, Diaz R, et al. Lipoprotein(a) lowering by alirocumab reduces the total burden of cardiovascular events independent of low-density lipoprotein cholesterol lowering: ODYSSEY OUTCOMES trial. Eur Heart J. 2020;41:4245-55.

72. Wilson DP, Jacobson TA, Jones PH, Koschinsky ML, McNeal CJ, Nordestgaard BG, et al. Use of lipoprotein(a) in clinical practice: a biomarker whose time has come. A scientific statement from the National Lipid Association. J Clin Lipidol. 2019;13(3): 374-92.

73. Roeseler E, Julius U, Heigl F, Spitthoever R, Heutling D, Breitenberger $\mathrm{P}$, et al. Lipoprotein apheresis for lipoprotein(a)associated cardiovascular disease: prospective 5 years of followup and apolipoprotein(a) characterization. Arterioscler Thromb Vasc Biol. 2016;36(9):2019-27.
74. Schettler VJJ, Neumann CL, Peter C, et al. Lipoprotein apheresis is an optimal therapeutic option to reduce increased Lp(a) levels. Clin Res Cardiol Suppl. 2019;14(Suppl 1):33-8.

75. Tsimikas S, Karwatowska-Prokopczuk E, Gouni-Berthold I, Tardif JC, Baum SJ, Steinhagen-Thiessen E, et al. Lipoprotein(a) reduction in persons with cardiovascular disease. N Engl J Med. 2020;382(3):244-55.

76. Koren M, Moriarty P, Neutel J, et al. Abstract 13951: Safety, tolerability and efficacy of singledose Amg 890, a novel Sirna targeting $\mathrm{Lp}(\mathrm{a})$, in healthy subjects and subjects with elevated Lp(a). Circulation. 2020;142:A13951.

77. Ferri N, Corsini A, Sirtori C, Ruscica M. PPAR-alpha agonists are still on the rise: an update on clinical and experimental findings. Expert Opin Investig Drugs. 2017;26(5):593-602.

78. Dubois V, Eeckhoute J, Lefebvre P, Staels B. Distinct but complementary contributions of PPAR isotypes to energy homeostasis. J Clin Invest. 2017;127(4):1202-14.

79. Botta M, Audano M, Sahebkar A, Sirtori CR, Mitro N, Ruscica M. PPAR agonists and metabolic syndrome: an established role? Int J Mol Sci. 2018 Apr 14;19(4):1197.

80. Norata GD, Tsimikas S, Pirillo A, Catapano AL. Apolipoprotein C-III: from pathophysiology to pharmacology. Trends Pharmacol Sci. 2015;36(10):675-87.

81. Preidis GA, Kim KH, Moore DD. Nutrientsensing nuclear receptors PPAR $\alpha$ and FXR control liver energy balance. J Clin Invest. 2017 Apr 3;127(4):1193-201.

82. Kersten S. Integrated physiology and systems biology of PPARalpha. Mol Metab. 2014;3(4):354-71.

83. Zandbergen F, Plutzky J. PPARalpha in atherosclerosis and inflammation. Biochim Biophys Acta. 2007;1771(8):972-82.

84. Sirtori CR, Yamashita S, Greco MF, Corsini A, Watts GF, Ruscica M. Recent advances in synthetic pharmacotherapies for dyslipidaemias. Eur J Prev Cardiol. 2020;27(15):1576-96.

85. Yamashita S, Masuda D, Matsuzawa Y. Pemafibrate, a new selective PPARalpha modulator: drug concept and its clinical applications for dyslipidemia and metabolic diseases. Curr Atheroscler Rep. 2020;22(1):5.

86. Ishibashi S, Arai H, Yokote K, Araki E, Suganami H, Yamashita S, et al. Efficacy and safety of pemafibrate (K-877), a selective peroxisome proliferator-activated receptor alpha modulator, in patients with dyslipidemia: Results from a 24-week, randomized, double blind, active-controlled, phase 3 trial. J Clin Lipidol. 2018;12(1):173-84.

87. Arai H, Yamashita S, Yokote K, Araki E, Suganami H, Ishibashi $\mathrm{S}$, et al. Efficacy and safety of pemafibrate versus fenofibrate in patients with high triglyceride and low HDL cholesterol levels: a multicenter, placebo-controlled, double-blind, randomized trial. J Atheroscler Thromb. 2018;25(6):521-38.

88. Arai H, Yamashita S, Yokote K, Araki E, Suganami H, Ishibashi S. Efficacy and safety of K-877, a novel selective peroxisome proliferator-activated receptor alpha modulator (SPPARMalpha), in combination with statin treatment: two randomised, doubleblind, placebo-controlled clinical trials in patients with dyslipidaemia. Atherosclerosis. 2017;261:144-52.

89. Sirtori CR, Galli C, Franceschini G. Fraudulent (and non fraudulent) fatty acids for human health. Eur J Clin Invest. 1993;23(11):686-9.

90. Calder PC. Mechanisms of action of (n-3) fatty acids. J Nutr. 2012;142(3):592S-9S.

91. Masters C. Omega-3 fatty acids and the peroxisome. Mol Cell Biochem. 1996;165(2):83-93.

92. Burke MF, Burke FM, Soffer DE. Review of cardiometabolic effects of prescription omega-3 fatty acids. Curr Atheroscler Rep. 2017;19(12):60.

93. Buoite Stella A, Gortan Cappellari G, Barazzoni R, Zanetti M: Update on the impact of omega 3 fatty acids on inflammation, 
insulin resistance and sarcopenia: a review. Int J Mol Sci. 2018 Jan 11;19(1):218.

94. Bhatt DL, Steg PG, Miller M, Brinton EA, Jacobson TA, Ketchum $\mathrm{SB}$, et al. Cardiovascular risk reduction with icosapent ethyl for hypertriglyceridemia. N Engl J Med. 2019;380(1):11-22.

95. Bhatt DL, Steg PG, Miller M, Brinton EA, Jacobson TA, Ketchum SB, et al. Effects of icosapent ethyl on total ischemic events: from REDUCE-IT. J Am Coll Cardiol. 2019;73(22): 2791-802.

96. Budoff MJ, Bhatt DL, Kinninger A, Lakshmanan S, Muhlestein JB, le VT, et al. Effect of icosapent ethyl on progression of coronary atherosclerosis in patients with elevated triglycerides on statin therapy: final results of the EVAPORATE trial. Eur Heart J. 2020;41:3925-32.

97. Nicholls SJ, Lincoff AM, Garcia M, Bash D, Ballantyne CM, Barter PJ, et al. Effect of high-dose omega-3 fatty acids vs corn oil on major adverse cardiovascular events in patients at high cardiovascular risk: the STRENGTH randomized clinical trial. JAMA. 2020;324:2268-80.

98. Kastelein JJP, Stroes ESG. FISHing for the miracle of eicosapentaenoic acid. N Engl J Med. 2019;380(1):89-90.

99. Lakshmanan S, Shekar C, Kinninger A, Dahal S, Onuegbu A, Cai $\mathrm{AN}$, et al. Comparison of mineral oil and non-mineral oil placebo on coronary plaque progression by coronary computed tomography angiography. Cardiovasc Res. 2020;116(3):479-82.

100. Graham MJ, Lee RG, Brandt TA, Tai LJ, Fu W, Peralta R, et al. Cardiovascular and metabolic effects of ANGPTL3 antisense oligonucleotides. N Engl J Med. 2017;377(3):222-32.

101.• Gaudet D, Karwatowska-Prokopczuk E, Baum SJ, et al. Vupanorsen, an $\mathrm{N}$-acetyl galactosamine-conjugated antisense drug to ANGPTL3 mRNA, lowers triglycerides and atherogenic lipoproteins in patients with diabetes, hepatic steatosis, and hypertriglyceridaemia. Eur Heart J. 2020; In this phase 2 study, the antisense oligonucleotide Vupanorsen results in a favourable lipid/lipoprotein profile and provides a potential strategy for residual cardiovascular risk reduction. Eur Heart J. 2020;41(40): 3936-45

102. D'Erasmo L, Di Costanzo A, Gallo A, Bruckert E, Arca M. ApoCIII: A multifaceted protein in cardiometabolic disease. Metabolism. 2020 Dec;113:154395.

103. van Capelleveen JC, Lee SR, Verbeek R, Kastelein JJP, Wareham NJ, Stroes ESG, et al. Relationship of lipoprotein-associated apolipoprotein C-III with lipid variables and coronary artery disease risk: the EPIC-Norfolk prospective population study. J Clin Lipidol. 2018;12(6):1493-501 e1411.

104. Kanter JE, Shao B, Kramer F, Barnhart S, Shimizu-Albergine M, Vaisar T, et al. Increased apolipoprotein $\mathrm{C} 3$ drives cardiovascular risk in type 1 diabetes. J Clin Invest. 2019;129(10):4165-79.

105. Barr SI, Kottke BA, Mao SJ. Postprandial exchange of apolipoprotein C-III between plasma lipoproteins. Am J Clin Nutr. 1981;34(2):191-8.

106. Jorgensen AB, Frikke-Schmidt R, Nordestgaard BG, TybjaergHansen A. Loss-of-function mutations in APOC3 and risk of ischemic vascular disease. N Engl J Med. 2014;371(1):32-41.

107. Taskinen MR, Packard CJ, Boren J. Emerging evidence that ApoC-III inhibitors provide novel options to reduce the residual CVD. Curr Atheroscler Rep. 2019;21(8):27.

108. Khetarpal SA, Zeng X, Millar JS, Vitali C, Somasundara AVH, Zanoni $\mathrm{P}$, et al. A human APOC3 missense variant and monoclonal antibody accelerate apoC-III clearance and lower triglyceriderich lipoprotein levels. Nat Med. 2017;23(9):1086-94.

109. Gaudet D, Alexander VJ, Baker BF, Brisson D, Tremblay K, Singleton W, et al. Antisense inhibition of apolipoprotein C-III in patients with hypertriglyceridemia. N Engl J Med. 2015;373(5):438-47.
110. Witztum JL, Gaudet D, Freedman SD, Alexander VJ, Digenio A, Williams KR, et al. Volanesorsen and triglyceride levels in familial chylomicronemia syndrome. N Engl J Med. 2019;381(6):531-42.

111. Ooi EM, Barrett PH, Chan DC, Watts GF. Apolipoprotein C-III: understanding an emerging cardiovascular risk factor. Clin Sci (Lond). 2008;114(10):611-24.

112. Fogacci F, Norata GD, Toth PP, Arca M, Cicero AFG. Efficacy and safety of volanesorsen (ISIS 304801): the evidence from phase 2 and 3 clinical trials. Curr Atheroscler Rep. 2020;22(5):18.

113. Alexander VJ, Xia S, Hurh E, Hughes SG, O'Dea L, Geary RS, et al. $\mathrm{N}$-acetyl galactosamine-conjugated antisense drug to APOC3 mRNA, triglycerides and atherogenic lipoprotein levels. Eur Heart J. 2019;40(33):2785-96.

114. Qamar A, Libby P, Bhatt DL. Targeting RNA to lower triglycerides: long strides from short molecules. Eur Heart J. 2019 Sep 1;40(33):2797-800.

115. Santos RD, Stein EA, Hovingh GK, Blom DJ, Soran H, Watts GF, et al. Long-term evolocumab in patients with familial hypercholesterolemia. J Am Coll Cardiol. 2020;75(6):565-74.

116. Santos RD, Ruzza A, Hovingh GK, Wiegman A, Mach F, Kurtz $\mathrm{CE}$, et al. Evolocumab in pediatric heterozygous familial hypercholesterolemia. N Engl J Med. 2020;383(14):1317-27.

117. Adam RC, Mintah IJ, Alexa-Braun CA, Shihanian LM, Lee JS, Banerjee $\mathrm{P}$, et al. Angiopoietin-like protein 3 governs LDLcholesterol levels through endothelial lipase-dependent VLDL clearance. J Lipid Res. 2020;61(9):1271-86.

118. Wu L, Soundarapandian MM, Castoreno AB, Millar JS, Rader DJ. LDL-Cholesterol reduction by ANGPTL 3 inhibition in mice is dependent on endothelial lipase. Circ Res. 2020;127(8):1112-4.

119. Domanski MJ, Tian X, Wu CO, Reis JP, Dey AK, Gu Y, et al. Time course of LDL cholesterol exposure and cardiovascular disease event risk. J Am Coll Cardiol. 2020;76(13):1507-16.

120.• Ray K, Molemans B, Schoonen W, et al. EU-wide cross-sectional observational study of lipid-modifying therapy use in secondary and primary care: the DA VINCI study. Eur J Prev Cardiol. 2020; In the context of lipid lowering approaches, there is a gap between clinical guidelines and clinical practice. In clinical care, there is the need of a greater utilization of non-statin lipid-lowering therapies in combination with statins for patients at highest risk.

121. Kam N, Perera K, Zomer E, Liew D, Ademi Z. Inclisiran as adjunct lipid-lowering therapy for patients with cardiovascular disease: a cost-effectiveness analysis. Pharmacoeconomics. 2020;38(9):1007-20.

122. Koskinas KC, Gencer B, Nanchen D, et al. Eligibility for PCSK9 inhibitors based on the 2019 ESC/EAS and 2018 ACC/AHA guidelines. Eur J Prev Cardiol. 2020:2047487320940102.

123. Iitake C, Masuda D, Koseki M, Yamashita S. Marked effects of novel selective peroxisome proliferator-activated receptor alpha modulator, pemafibrate in severe hypertriglyceridemia: preliminary report. Cardiovasc Diabetol. 2020;19(1):201.

124. Boden WE, Bhatt DL, Toth PP, Ray KK, Chapman MJ, Luscher TF. Profound reductions in first and total cardiovascular events with icosapent ethyl in the REDUCE-IT trial: why these results usher in a new era in dyslipidaemia therapeutics. Eur Heart J. 2020;41(24):2304-12.

125. Poppe K, Wells S, Jackson R, Doughty R, Kerr A. Predicting cardiovascular disease risk across the atherosclerotic disease continuum. Online ahead of print. Eur J Prev Cardiol. 2021 Jan 18;zwaa168.

126. Sharma G, Martin SS, Blumenthal RS. Effects of omega-3 fatty acids on major adverse cardiovascular events: what matters most: the drug, the dose, or the placebo? JAMA. 2020 Dec 8;324(22):2262-4.

Publisher's Note Springer Nature remains neutral with regard to jurisdictional claims in published maps and institutional affiliations. 